\title{
SOBRE OS FILMES EM TEU NOME, DE PAULO NASCIMENTO, E BATISMO DE SANGUE, DE HELVÉCIO RATTON
}

\author{
José Augusto Lima Pachêco
}

Resumo: O propósito deste trabalho é refletir a respeito da prática da tortura no período da ditadura militar no Brasil durante os anos 70 a partir de dois filmes: Em teu nome (2009), de Paulo Nascimento, e Batismo de sangue (2006), de Helvécio Rattton. A primeira parte apresenta o drama político e histórico como um dos gêneros explorados pelo cinema brasileiro, configurando-se como uma vertente autoral que provoca a reflexão sobre os conturbados anos de chumbo da ditadura brasileira, seja como documentário ou ficção. A seguir, a tortura, o exílio, o processo de adaptação literária para o cinema na proposta intimista de Paulo Nascimento e denúncia realista de Helvécio Rattton.

Palavras-chave: Tortura, exílio, ditadura, adaptação.

\begin{abstract}
The focus of this work is to discuss about the torturing practice in the period of dictatorship government in Brazil during the 70's by means of two films: Em teu nome ( 2009) directed by Paulo Nascimento and Batismo de sangue (2006) directed by Helvécio Ratton. Firstly is presented the political and historical dilemma such a genre well exploited in the Brazilian films (fiction or documentary) if observed like an authorial approach which evokes a reflection about the hard times of the Brazilian dictatorship. Secondly, the torture, the exile, and the process of literary adaptation to the screen by the intimate looking of Paulo Nascimento and the realistic denounce of Helvécio Ratton.
\end{abstract}

Keywords: Torture, exile, dictatorship, adaptation.

${ }^{1}$ Mestrando em Estudos Literários da UFPA. E-mail: aupacheco@gmail.com. 


\section{INTRODUÇÃO}

O que torna os filmes de Paulo Nascimento e Helvécio Ratton exemplos de uma opção temática, produto de uma vertente cinematográfica que reside e resiste na autoralidade de seus realizadores? Quais os elementos explorados ou priorizados para se debruçarem em um período histórico marcado pela perseguição e tortura dos chamados anos de chumbo da ditadura militar no Brasil?

Em teu nome, realizado em 2009, e Batismo de Sangue, concluído em 2006, fazem parte de uma seleção de filmes produzidos que se amparam nos procedimentos do drama político para lançarem novas luzes sobre o conturbado início dos anos 70, em que o Brasil vivia o endurecimento da ditadura militar.

O drama político, este gênero que tem como recorte a resistência da sociedade civil organizada e a reação de grupos políticos que optaram pela luta armada para enfrentar o regime, já rendeu outros títulos com base na adaptação literatura \& cinema, como: Nunca fomos tão felizes (1984), dirigido por Murilo Salles e com roteiro escrito por Alcione Araújo e Jorge Durán, baseado no conto "Alguma coisa urgentemente", de João Gilberto Noll; Lamarca (1994), dirigido por Sérgio Rezende e baseado em livro de José Emiliano e Miranda Oldack, de título Lamarca, o capitão da guerrilha, biografia do militar e guerrilheiro Carlos Lamarca; e O que é isso, companheiro? (1997), de Bruno Barreto, com roteiro parcialmente baseado no livro homônimo de Fernando Gabeira, publicado em 1979. Há também outros títulos com roteiros originais ficcionais ou baseados em fatos históricos, como $O$ ano em que meus pais saíram de férias (2006), de Cao Hamburger; e longas que se apropriam da narrativa policial, a exemplo de Pra frente Brasil (1982), de Roberto Farias, e Ação entre amigos (1998), de Beto Brandt.

São narrativas fílmicas que não se pretendem isolados de outros setores da sociedade, no caso, a conjuntura política deste conturbado período histórico, e se mostram imbricados nas tensas, complexas relações de poder sujeito e estado, em que seus protagonistas e coadjuvantes estão necessariamente envolvidos, como observam os teóricos Vanoye e Goliot-Lété (1994, p. 56):

Em um filme, qualquer que seja seu projeto (descrever, distrair, criticar, denunciar, militar), a sociedade não é propriamente mostrada, é encenada. Em outras palavras, o filme opera escolhas, organiza elementos entre si, decupa no real e no imaginário, constrói um mundo possível que mantém relações complexas com o mundo real: pode ser em parte seu reflexo, mas também pode ser sua recusa (ocultando aspectos importantes do mundo real, idealizando, amplificando certos defeitos, propondo um contramundo [...]

O real, o imaginário fazem parte do processo da criação literária e sua adaptação para o cinema, no caso, uma recriação, processo de transposição de uma linguagem para outra que pode ter como base as experiências vividas pelo autor, experiências vivenciadas por terceiros, assim como ocorrências imaginadas, suavizadas ou potencializadas.

Nos filmes como Nunca fomos tão felizes, Lamarca e O que é isso, companheiro?, as adaptações funcionam como uma recriação da atmosfera, do conteúdo proposto da obra 
original. Como adaptações de uma literatura testemunhal (experiências vivenciadas pelo autor), a liberdade poética do recriador corre riscos inerentes à especificidade do suporte, meio ou veículo que se propõe a realizar a nova leitura.

No livro, os leitores embarcam numa viagem de operações semânticas e sintáticas, devidamente materializada em palavras, ao mesmo tempo em que o texto aprofunda a noção de tempo. O filme oferece a imagem pronta por meio de escolhas estéticas, daí a relação tensa e produtiva de perdas e ganhos, lacunas e acréscimos por meio de planos, contraplanos, lentes, marcação de atores, iluminação, sonoplastia, entre outros procedimentos.

O conflito inicial cedendo espaço para a reelaboração de obras consagradas ou recentes, subvertendo ou reforçando valores na busca de novos pontos de vista, novos significados, novas produções de sentido.

Conhecemos o gênero documentário como uma vertente do cinema compromissado em retratar a realidade ou um aspecto da realidade de uma forma imediata e realista, o que não indica necessariamente sua representação total do real. Assim como a literatura testemunhal, o documentário se afirma como uma representação autoral, subjetiva da realidade. Como gênero que agrupa vários subgêneros, temos documentários: sociais, políticos, biográficos, históricos, experimentais/poéticos, etnográficos, e docudramas.

Seguindo a tradição do documentário que lanças novas luzes sobre o período da ditadura militar brasileira, temos os exemplos de Que bom te ver viva (1989), de Lucia Murat, Hércules 56 (2006), de Silvio Da-Rin, e o premiado Cabra marcado para morrer (1984), de Eduardo Coutinho, entre outros tantos.

Hoje, a indefinição de fronteiras entre documentário e cinema de ficção marca a produção contemporânea no Brasil e no mundo, se afirmando cada vez mais como um gênero híbrido. Que bom te ver viva (1989), de Lucia Murat, transita entre o ficcional e o documental com procedimentos distintos: luz teatral e luz natural para narrar os delírios de uma personagem anônima e das ex-presas políticas em vídeo. Hércules 56 (2006), de Silvio Da-Rin, opta pela memória de seus participantes num formato documental clássico (câmeras, microfones e técnicos) e a inserção de imagens de arquivo. Em Cabra marcado para morrer (1984), de Eduardo Coutinho, o filme dentro do filme apresenta um longa inicialmente produzido para ser ficção e que se transformou, posteriormente, um dos maiores documentários da cinematografia nacional. Metalinguagem a serviço da linguagem documental e política.

Na teledramaturgia, o exemplo mais contundente talvez seja Anos rebeldes, minissérie transmitida entre 14 de julho e 14 de agosto de 1992, tendo totalizado 20 capítulos. A minissérie foi inspirada nos livros: 1968 - O ano que não terminou, de Zuenir Ventura e Os carbonários, de Alfredo Sirkis, sendo escrita por Gilberto Braga e Sérgio Marques, com direção de Denis Carvalho.

Em 1968 - O ano que não terminou, de Zuenir Ventura, a narrativa é composta por personagens, obras e músicas do período relatado, como a atriz italiana Claudia Cardinale, Cesar Benjamin “Cesinha” (militante do Movimento Revolucionário 8 de Outubro), o capitão da guerrilha Carlos Lamarca, assim como músicos que, de formas variadas, participaram do combate ao regime militar: Geraldo Vandré, Chico Buarque e Caetano Veloso.

No livro Os carbonários, Alfredo Sirkis narra o período de outubro de 1967 a maio de 1971, num relato sobre o movimento estudantil de 1968 e como um jovem secundarista se 
torna um guerrilheiro urbano. Entram em foco o sequestro dos embaixadores da Alemanha e da Suíça e a libertação de 110 presos políticos e o enfraquecimento da guerrilha urbana.

\section{ADAPTAÇÃO}

O sujeito, o leitor/espectador, este viajante que presta tributo ao poder das palavras e imagens em movimento, pode interpretar uma obra em operações tão distintas como crítica, atualização do contexto, técnica utilizada, linguagem, temática, história, ideologia, etc., pois sendo um sujeito que interpreta a metáfora, um sujeito interpretante, sabe que não há uma única interpretação, uma leitura verdadeira no sentido de engessamento da interpretação, assim como a possibilidade de fidelidade na transposição de uma linguagem artística para outra. Em Palimpsestes (1982), Gerard Genette aponta para o termo 'transtextualidade', ou seja, a possibilidade de relações intertextuais em tudo o que coloca o texto em relação (manifesta ou secreta, voluntária ou involuntariamente) com os outros textos. Nesta possibilidade de relações transtextuais, segundo Genette, temos a Intertextualidade, que indica a co-presença de um ou mais textos entre outros textos, como é o caso da minissérie brasileira de televisão Anos rebeldes, que tem como base o processo de adaptação as obras testemunhais de Zuenir Ventura e Alfredo Sirkis.

O francês Yanick Mouren (1993), com base nas concepções de Genette, trabalha com a transposição da literatura em audiovisual (contos, novelas, romances) em três possibilidades: a Adaptação de uma única obra para um filme (como em Batismo de Sangue); a Contaminação, ou seja, mais de uma obra para uma linguagem audiovisual (a exemplo de Anos rebeldes, minissérie adaptada dos livros 1968 e Os carbonários); e a Narrativização, com a transposição de trabalhos não ficcionais (diários, relatos) para a adaptação ficcional (Olga, inspirado em biografia de Fernando Morais). São as chamadas transposições diegéticas, em que hipertexto audiovisual transporta seu hipotexto com modificações inevitáveis no quadro espacial, temporal, sem a preocupação de fidelidade com o texto original, com a liberdade estética para suprir ou acrescentar novas formas de recriação.

Como narrativa seriada no gênero de teledramaturgia, ágil e com elementos de suspense, a minissérie Anos rebeldes contou com a colaboração de Ricardo Linhares e Angela Carneiro, para, a princípio, recriar a atmosfera da revolução de 68, tendo como pano de fundo uma história de amor folhetinesca. O personagem João Alfredo, por exemplo, é livremente inspirado na trajetória de Alfredo Sirkis e os documentos em preto e branco reconstituídos pelo cineasta Silvio Tendler inseridos com imagens em $16 \mathrm{~mm}$, potencializam o caráter documental e ficcional da minissérie.

$\mathrm{Na}$ adaptação para a TV, uma cena considerada antológica é o assassinato da personagem Heloísa Andrade Brito, inspirada na estudante pernambucana Ranúsia Alves Rodrigues, que nos fim dos anos sessenta atuava na clandestinidade. Em 27 de outubro de 1973, Ranúsia foi assassinada a tiros na Praça Sentinela, Jacarepaguá (RJ), juntamente com Almir Custódio de Lima, Ramirez do Vale e Vitorino Alves, que morreram carbonizados dentro de um carro. Na adaptação, os guerrilheiros saem ilesos e Heloísa é eliminada ao mostrar a carteira de identidade, o que potencializa ainda a ação dramática. 
Exibida em julho e agosto de 1992, o mesmo período em que os estudantes "cara pintada" foram às ruas pelo impeachment do então presidente Collor de Mello, a canção Alegria, Alegria, de Caetano Veloso, voltou às paradas pelos meios de comunicação num exemplo de intertextualidades (literatura, cinema e música) como processo de adaptação num caso curioso: dois livros (1968 e Os carbonários) adaptados para a TV que geram uma outra obra, desta vez, para a narrativa seriada em teledramaturgia (a minissérie) e se estende, de volta ao mercado editorial com o livro Anos rebeldes, a versão literária da minissérie, lançada em maio de 2010. Nesta versão, a definição literal dos cenários, inserção de vários diálogos, pausas, sequências não incluídas e excluídas. O romance entre a individualista Maria Lúcia e o idealista João Alfredo durante os anos de chumbo, e a história do escritor Gilberto Braga, desde a juventude alienada nos anos rebeldes até tornar-se um escritor de televisão.

São obras de gêneros distintos (ficção, documentário, narrativa seriada), tendo como orientação temática o período da ditadura militar no Brasil. Porém, seus realizadores se utilizam de diferentes modos de narrar suas histórias, com a marca do período em que foram realizadas, como explica Paulo Antônio Pereira (1981, p. 168):

Toda obra reflete uma época, é verdade, mas toda obra autêntica, isto é, original (e aqui opomos original ao que é produzido em larga escala, com pequenas variações de um tema central ou modo de dizer já apresentado antes), toda obra de autor reflete a percepção que este autor tem do seu próprio mundo... pode-se perceber uma pessoa (o autor) tentando mostrar a outros (espectadores) suas ideias, sua sensibilidade estética, sua posição diante do mundo em que vivemos.

\section{EM TEU NOME E BATISMO DE SANGUE}

Em teu nome, produção gaúcha com base no relato Verás que um filho teu não foge à luta (de João Carlos Bona Garcia e Júlio Posenato), conta a história de Boni, um estudante de engenharia que adere a luta armada, apesar de dúvidas e medos sobre se este seria realmente o melhor caminho para combater o regime militar no Brasil.

Na primeira metade do filme, discute-se a validade, a legitimação da luta armada, sua dimensão como utopia, e a responsabilidade de ser jovem como agente de seu tempo, mesmo quando os processos midiáticos imperam, como as partidas de futebol televisionadas e a certeza de “... o povo não está nem aí”, em diálogo que provoca tanto os personagen como o espectador. Garcia é preso, torturado, mas por sorte não desaparece como tantos outros, sendo banido e trocado pelo embaixador suíço no chamado Grupo dos 70.

Com locações na França, Marrocos, Chile e Brasil, Em teu nome aposta numa proposta intimista, sem muita ação, numa reflexão afetiva deste conturbado período. A trilha sonora, de certa forma, assume o papel de componente narrativo deste que é o quarto filme de longa metragem do diretor Paulo Nascimento, composta por André Tento, com a participação do cantor e compositor Vitor Ramil, na cena de reunião de jovens na residência do protagonista. Na trilha, a canção se encaixa com a proposta reflexiva do diretor, observada no exílio do protagonista, uma saudade da terra, em dois trechos do título "Deixando o pago": 
Fui aumentando a distância

Deixar o rancho da infância

Coberto pela neblina

Nunca pensei que minha sina

Fosse andar longe do pago

E trago na boca o amargo

Dum doce beijo de china

Falam muito no destino

Até nem sei se acredito

Eu fui criado solito

Mas sempre bem prevenido

Indio do queixo torcido

Que se amansou na experiência

Eu vou voltar pra querência

Lugar onde fui parido

Batismo de sangue é baseado no livro homônimo de Frei Betto, lançado originalmente em 1983 e vencedor do prêmio Jabuti. A proposta de Helvécio Ratton é realizar um recorte histórico realista sobre a tortura, a desesperança e as cinzas de sonho que desabaram sobre as cabeças e os corpos dos frades dominicanos (Tito, Betto, Oswaldo, Fernando e Ivo) que ao final dos anos 60, tornam-se uma das mais fortes resistências ao regime de exceção, com apoio logístico e financeiro ao grupo Ação Libertadora Nacional, então sob o comando de Carlos Marighella.

Envolvente e angustiante, o filme de Ratton também reserva uma cena em que a participação da sociedade é colocada em questão com a pergunta: "Como vamos conscientizar o povo? E como resposta engajada: “Ação, luta armada, combate!”. A pergunta é feita no momento do encontro dos freis dominicanos com os combatentes envolvidos na luta armada numa espécie de depósito, armazém, logo no início do filme.

Com cenas de tortura longas e mais explícitas que o filme de Paulo Nascimento, Batismo de Sangue, releva a verdadeira Via Crúcis dos freis acusados de traidores da igreja e da pátria, posteriormente julgados e sentenciados a quatro anos de reclusão em regime fechado. Aqui, a opção é adaptar o livro de Frei Betto com imagens em movimento que optam em filmar de forma impactante, com sequências de espancamento, humilhação e choques elétricos, inseridos de forma a intensificar, com ruídos e barulhos agonizantes, o sofrimento dos protagonistas.

Uma tendência da chamada pós-modernidade na arte contemporânea é o hiper-realismo, que chama atenção pelo modo de caracterizar a realidade de forma crua, possibilitando, inclusive, a perda da habilidade de distinguir a realidade da fantasia. Mais difundido a partir dos anos 60, o termo "hiper-realismo" é usado para denominar uma tendência artística comum à literatura, ao cinema e às artes visuais, presente nos textos do escritor Rubem Fonseca, nos filmes de Claudio Assis e Quentin Tarantino, pelas cenas chocantes e de brutalidade, na proposta de amplificação do impacto, da realidade.

Em Batismo de sangue, as cenas hiper-realistas estão presentes nas sessões de tortura 
comandadas pelo delegado Fleury e no aniquilamento psíquico e físico do personagem frei Tito. Desse modo, a hiper-realidade das imagens encenadas, em diálogos ásperos, às vezes, aos gritos, reafirmam o drama político como um gênero eficaz para abordar o período da ditadura militar no Brasil. No caso do filme de Helvécio Ratton, para dar conta da prática da tortura neste período, as imagens hiper-realistas pretendem amplificar a sensação de choque no espectador; escolhas necessárias para causar o impacto visual do filme.

Por outro lado, temos o tratamento intimista utilizado pelo cineasta Paulo Nascimento em Em teu nome. O questionamento do ser, a introspecção, e o estar no mundo, são algumas características do romance intimista. É uma literatura que bebe na fonte da crise dos personagens, em sua consciência e inconsciência, observada nos textos de Virginia Woolf, James Joyce, entre outros. No Brasil, a partir da terceira geração do movimento modernista (1945-1978), a prosa (no romance e no conto) se caracteriza por uma literatura intimista e introspectiva, marcadamente na obra de Clarice Lispector. São textos que apresentem reflexões acerca dos questionamentos individuais através do fluxo de consciência, porém com fendas abertas para a visão de mundo do autor. No cinema, particularmente no drama político, podemos citar o tom intimista que marca o fotograma de filmes como O Ano em que meus pais saíram de férias, de Cao Hamburger, sob a ótica de um menino; e Nunca fomos tão felizes, de Murilo Sales, sob a ótica de um adolescente, em que os diálogos são em pequeno número, dando lugar ao monólogo interior e a longos silêncios.

No filme Em teu nome, ao contar a história de Boni, um estudante de Engenharia que adere à luta armada, dúvidas e medos questionam se esta realmente seria a melhor solução. É o desencanto sob uma ótica humanista e poética, ao narrar uma história de amor que ultrapassa as fronteiras do conjugal para alcançar o amor à liberdade, à pátria, num filme que nos fala sobre a capacidade de superação do personagem Boni, que, ao seu modo, nos faz crer o quanto foi dolorida a imposição do exílio e sofrimento da tortura, e a sensação final de que fazer política é muito mais complexo do que manejar armas.

Em Batismo de sangue, o livro homônimo, apoiado em relatos reais, aponta mais de dez dominicanos envolvidos no movimento contra o regime militar. Na adaptação, o número ficou concentrado em cinco frades: Tito, Betto, Ivo, Fernando e Oswaldo, com narrativa centrada em Frei Tito, como certo protagonismo dos demais. É um exemplo de adaptações de livros de caráter testemunhal, que descrevem fatos vividos pelo seu autor, como o bestseller Estação Carandiru, de Drauzio Varella, dirigido por Hector Babenco; Cidade de Deus, de Paulo Lins e adaptado por Fernando Meirelles e Kátia Lund; e Bicho de sete cabeças, com base em $O$ canto dos malditos de Austregésilo Carrano, com direção de Laís Bodanski. Assim como Batismo de sangue, os filmes citados são adaptações que trabalham a duplicidade do tempo: o tempo da montagem do filme e o tempo narrativo do livro, cada um com suas especificidades, acréscimos, lacunas e contribuições, como defende a professora Maria de Lourdes Abreu de Oliveira (1987, p. 27-28):

Enquanto na narrativa verbal o narrador delimita detalhes, selecionando-os e colocando-os em ordem de importância para o leitor, o cineasta deixa-os em aberto para o público, os detalhes não sendo 'afirmados', mas simplesmente 'apresentados’ num leque de possibilidades de escolha. 
Nos relatos do livro, por quarenta e dois dias Frei Tito foi torturado a choques elétricos nos ouvidos e genitais, ao pau-de-arara, palmatórias e queimaduras de cigarro, entre outros sadismos, como a "hóstia sagrada" (dois eletrodos com corrente elétrica). A hóstia também se insere como elemento dramático na sequência da missa rezada nos porões do DOPS, quando não havia hóstias, sendo realizada com biscoitos, em clima de catacumba que remete aos primórdios do cristianismo.

\section{O EXÍLIO}

O exílio (este estado de estar longe da própria casa, expatriação voluntária ou forçada de um indivíduo) surge no filme Em teu nome como o local privilegiado da reflexão sobre as convicções do grupo em que Boni fazia parte. O exílio como distância necessária para questionamento da prática revolucionária, o conhecimento da sociedade chilena de outra maneira e a compreensão de que "para mudar a realidade é preciso primeiro entendê-la..." O exílio como preparação para o que está por vir e o que pode ser feito agora, a exemplo da participação no Comitê Brasileiro da Luta pela Anistia. E o exílio como preparação para outras práticas, como a volta ao país que tem atenções voltadas para o processo de redemocratrização ao final dos anos 70. O exílio como cenário e proposta intimista do diretor Paulo Nascimento e sua contribuição para o entendimento do processo de militarização e supressão das liberdades civis na América Latina.

Em Batismo de sangue, ao ser exilado no Chile, Itália e França, Tito (Caio Blat) ficara obsessivo dos traumas da tortura com o delegado Sérgio Paranhos Fleury. Seu suicídio é uma tentativa de livrar-se do julgo psicológico e paranóico de um período em que não conseguiu se libertar, uma espécie de resistência em outro plano: "Melhor morrer do que perder a vida", escreveu o frade antes de falecer. O suicídio como alternativa para aliviar a tortura interna também foi apresentado no filme Em teu nome, por meio da personagem Lenora, interpretada por Sílvia Buarque, infelizmente desenvolvida de forma mínima, como um personagem secundário, necessariamente coadjuvante.

Sem suportar as lembranças do período em foi torturada, Lenora tira sua vida como aquela personagem que entra no filme e não sabemos muito bem suas motivações, sugeridas apenas de forma ilustrativa, ao contrário da elaboração do personagem de Frei Tito em Batismo de sangue. No filme de Paulo Nascimento, Lenora se reencontra com os amigos pouco antes de ir para o Chile e o espectador descobre, por meio de uma revelação, que um dos seus torturados se masturbava em seu rosto. Perda moral e física sofrida com as dores do corpo e da mente (lembranças).

O exílio, como espaço do impacto emocional causado pela tortura, expulsão e humilhação, é abordado de três formas.

1 - O desfecho trágico dos que não superaram a dor sofrida nos cárceres e o deslocamento em terra estrangeira. Este deslocamento é observado nos personagens do frei Tito e de Lenora, em cenas solitárias e mesmo em grupo com olhares distantes, como se estivessem incomunicáveis, no isolamento, no desterro.

2 - A superação da dor pela militância em terra estrangeira, por meio de panfletagens, 
a formação do Comitê Brasileiro pela Anistia e as articulações para o processo de redemocratização, observados no personagem de Boni, na maioria das cenas retratado com a família, combatentes e populares engajados.

3 - O exílio como processo de recomeço longe do Brasil, que fica evidente quando o professor (de Em teu nome) diz que fica na Europa, que não consegue voltar mais. A certa altura do filme, ele se questiona: "Acho que agora está na hora de eu saber verdadeiramente quem eu sou. Ou quem eu deveria ter sido. Não sei. Talvez eu volte para a religião, talvez não mude nada. A verdade é que eu me sinto um estrangeiro em qualquer lugar”.

Tanto Em teu nome como em Batismo de sangue, alguns pontos explorados ora são parecidos, ora são diferentes:

1 - O processo de troca dos guerrilheiros para libertar o embaixador da Suiça, Giovani Enrico Bucher, seqüestrado pela Vanguarda Popular Revolucionário (VPR), em 1971. Em Batismo de sangue, a troca é dada pelo exílio de Frei Tito, enquanto outros frades aguardam em prisão de regime fechado. Em teu nome, o exílio dos envolvidos é realizado em grupo, mesmo disperso em diversos países e reencontros finais.

2 - O sentimento de ser e estar estrangeiro, dentro de lugares que em que não há o sentimento de pertencimento: o espaço, o clima, o idioma. O presente como tempo da obrigação, não devidamente vivido. O presente como produto de uma ação do passado. O futuro como um aceno sombrio e nulo (Frei Tito) e esperançado como os novos ventos da anistia (Boni).

3 - A tortura, no filme de Paulo Nascimento é apresentada de maneira comedida, em planos rápidos. No filme de Helvécio Ratton, as cenas de tortura se apresentam de modo imperativo, hiper-realista, utilizada como instrumento de Estado para arrancar informações que mudaram o curso da História.

Portanto, Batismo de sangue e Em teu nome são dois títulos da recente cinematografia brasileira que se debruçaram sobre o período da ditadura militar de acordo com a direção e roteiro de seus realizadores. As duas produções fazem reflexão sobre luta armada "em nome do povo", sem contar com o apoio popular. Uma luta sem apoio das massas, feita por pequenos grupos. Planos, enquadramentos, fotografia, diálogos, luz e montagem são os procedimentos da linguagem cinematográfica que se organizam na tela, para cada diretor, a seu modo, narrar um período conturbado e pouco discutido da História do Brasil.

\section{REFERÊNCIAS}

BRAGA, Gilberto. Anos rebeldes: os bastidores de criação de uma minissérie. Rio de Janeiro: Rocco. 2010.

FEIJÓ, Sara Duarte. Em teu nome... e Batismo de sangue: formas cinematográficas de representar o exílio na ditadura brasileira. Disponível em: revistas.pucsp.br/index.php/revph/article/view/4431.

Acesso em: 01/07/2012. 
OLIVEIRA, Maria de Lourdes Abreu de. Montagem no filme e no romance. Revista Vozes, Petrópolis, v. LXXXI, n. 3, 1987.

PALMA, Glória (Org). Literatura e cinema. A demanda do Santo Gral \& Matrix - Eurico, o Presbítero \& A máscara do Zorro. Bauru: EDUSC, 2004.

PEDROSA, Celia de Moraes Rego. O Discurso hiperrealista (Rubem Fonseca e André Gide). Rio de Janeiro: PUC. 1977

PEREIRA, Paulo Antônio. Imagens do movimento: introduzindo ao cinema. Belo Horizonte: Vozes, 1981.

VANOYE, Francis, GOLIOT-LÉTÉ, Anne. Ensaio sobre análise fílmica. Campinas: Papirus, 1994.

GENETTE, Gérard. Palimpsestes - La littérature au second degré. Paris: Seuil, 1982.

MOUREN, Yanick. Le film comme hypertexte - Typologie des transpositions du livre au film. Poétique. Paris: Seuil, 1993.

\section{FILMOGRAFIA}

BATISMO de sangue. Direção e produção de Helvecio Ratton. Roteiro de Dani Patarra e Helvécio Ratton. Brasil (2007). 1 DVD (110 min), Cor.

EM TEU nome. Direção de Paulo Nascimento. Produção de Beto Rodrigues e Marilaine Castro da Costa. Roteiro de Paulo Nascimento. Brasil (2009). 1 DVD (102 min), Cor. 